\title{
AVALIAÇÃO DE FRANQUIAS EMPRESARIAIS POR MEIO DE MÚLTIPLOS DE RECEITA: UM SACRILÉGIO ACADÊMICO DESCULPÁVEL
}

DOI: 1014211/regepe.v5i2.367

Artigo recebido em:20/04/2016

Artigo aprovado em: 07/07/2016

\begin{abstract}
Rodolfo Leandro de Faria Olivo - Faculdade Fia de Administração e Negócios - FFIA ${ }^{1}$
Leandro José Morilhas - Faculdade Fia de Administração e Negócios - FFIA ${ }^{2}$

Flávia Angeli Ghisi Nielsen - Faculdade Fia de Administração e Negócios - FFIA ${ }^{3}$

Daniel Estima de Carvalho - Faculdade Fia de Administração e Negócios - FFIA ${ }^{4}$
\end{abstract}

Resumo: O mercado de franquias no Brasil, apesar de movimentar bilhões de reais, é composto de milhares de unidades franqueadas, constituídas na forma de micro e pequenas empresas. Assim, a avaliação dessas unidades franqueadas, em geral, não utiliza o método do Fluxo de Caixa Descontado (FCD) devido às dificuldades da aplicação desse método a pequenas empresas. Contudo, faz uso, alternativamente, da avaliação por meio de múltiplos de receita, a qual sofre críticas acadêmicas. Por meio de um estudo de caso, neste artigo argumenta-se que especificamente para as franquias empresariais enquadradas como Micro e Pequenas Empresas (MPEs), devido a suas próprias características enquanto negócio, a utilização da avaliação por múltiplos é bastante razoável, convergindo em valores com a avaliação pelo FCD, sendo uma boa alternativa para a definição do valor da empresa. Desta forma, a prática de mercado de franquias para a sua avaliação em compras e vendas de unidades franqueadas, torna-se eficiente, mesmo que por outros métodos, uma vez que converge com a técnica acadêmica do Fluxo de Caixa Descontado, sendo que os múltiplos, nesse caso específico, refletem de forma razoável o valor intrínseco das franquias.

Palavras-chave: Franquias Empresariais; Avaliação de Empresas; Múltiplos de Receita.

\footnotetext{
${ }^{1}$ Endereço: Rua José Alves da Cunha Lima, 172, Vila Butantã, São Paulo-SP, CEP: 05360-050. Email: rodolfo.olivo@outlook.com

2 E-mail: leandrom@fia.com.br

3 E-mail: flaghisi@gmail.com

${ }^{4}$ E-mail: danielc@fia.com.br
}

OLIVO, R. L. F.; MORILHAS, L. J.; NIELSEN, F. A. G.; CARVALHO, D. E. Avaliação de franquias empresariais por meio de múltiplos de receita: um sacrilégio acadêmico desculpável. Revista de Empreendedorismo e Gestão de Pequenas Empresas, v.5, n.2, 2016. 


\title{
FRANCHISING VALUATION BY MEANS OF REVENUE MULTIPLES: AN EXCUSABLE ACADEMIC SACRILEGE
}

\begin{abstract}
The Brazilian franchising market, despite moving billions of reais, is composed of thousands of franchised units, organized as micro and small business. Thus, the evaluation of these franchised units generally does not use the method of Discounted Cash Flow (DCF) because of the difficulties of applying this method to small businesses. However, it makes use of evaluation through multiple revenue, which suffers academic criticism. Through a case study, this article argues that for the business franchises classified as micro and small enterprises (MSEs), due to its own characteristics as a business, the use of evaluation by multiple is quite reasonable, converging values with the evaluation by FCD, being a good alternative to the definition of the company's value. Thus, franchising market practice of sell and buy valuation is efficient, even using other methods, once converging to Discounted Cash Flow Technique, being the multiple, on this specific case, reflect franchising intrinsic value reasonably.
\end{abstract}

Keywords: Franchising; Business Valuation; Revenue Multiples.

\section{Introdução}

O mercado de franquias no Brasil movimentou o montante de 139,6 bilhões de reais em 2015 em 138 mil unidades franqueadas e 3,1 mil franqueadores (ABF, 2016). Devido ao significativo número de participantes desse mercado, existe a demanda pela avaliação do valor das franquias, seja para a compra e venda dessas entre franqueados, recompra por parte dos franqueadores ou mesmo para eventuais fusões e aquisições das redes de franquias.

Sabe-se que o método de avaliação mais utilizado é a avaliação por múltiplos, também conhecida como avaliação relativa. Ela é utilizada especialmente para a compra e venda de unidades franqueadas em funcionamento. De acordo com Damodaran (2007), apesar do fluxo de caixa descontado ser bastante popular na teoria, há evidências de que a maioria dos ativos é avaliada em bases relativas, isto é, a maioria das regras práticas dos investimentos baseia-se nos múltiplos.

OLIVO, R. L. F.; MORILHAS, L. J.; NIELSEN, F. A. G.; CARVALHO, D. E. Avaliação de franquias empresariais por meio de múltiplos de receita: um sacrilégio acadêmico desculpável. Revista de Empreendedorismo e Gestão de Pequenas Empresas, v.5, n.2, 2016. 
Segundo o autor, o uso de múltiplos demanda menos tempo e recursos do que a avaliação de fluxo de caixa descontado e é mais fácil de entender e de defender (DAMODARAN, 2007). Para analistas ou investidores que enfrentam restrições de tempo, acesso a informações ou mesmo conhecimento técnicos, a avaliação relativa oferece uma alternativa mais rápida e fácil, o que se enquadra no caso da compra e venda de unidades franqueadas.

Essa constatação da prática da utilização da avaliação por múltiplos no mercado de franquias do Brasil justifica a indagação básica dessa pesquisa: Quais as vantagens da avaliação por múltiplos no caso de pequenas empresas franqueadas? Em geral, esse método de análise é considerado academicamente fraco, uma vez que utiliza muitas simplificações para realizar a avaliação, ou seja, o método de múltiplos preza mais pela simplicidade e aplicabilidade do que pelo rigor técnico (DAMODARAN, 2007).

Por tais razões, o presente artigo tem por objetivo investigar as possíveis vantagens da utilização do método de múltiplos em substituição ao fluxo de caixa descontado para avaliação de pequenas empresas franqueadas.

Em pesquisa bibliográfica nas bases de dados Google Acadêmico e EbscoHost, não foi encontrado nenhum artigo científico especificamente versando sobre a aplicação do método de múltiplos em comparação com o fluxo de caixa descontado em pequenas empresas franqueadas. Assim, justifica-se a presente pesquisa no sentido de diminuir a lacuna existente na literatura acadêmica brasileira sobre o referido tema.

\section{Conceituação de Franquias Empresariais}

O objeto de estudo deste trabalho são as franquias de micro e pequeno porte no Brasil. O termo franquia, franchise em inglês, que dá origem ao termo franquear, é definido por Cherto (2005, p.15) como sendo: "uma das estratégias de que uma organização pode fazer uso para escoar seus produtos e serviços levandoos até o mercado". Dessa forma, o autor coloca ênfase na questão mercadológica da distribuição como o diferencial das franquias, para o qual a essência do franchising 2016. 
consiste em replicar ou clonar, em diversos locais, um mesmo conceito de negócio. Em contraste com essa definição mais mercadológica, a IFA (International Franchise Association, 2011) promove a definição de franchising do Departamento de Comércio dos Estados Unidos:

\begin{abstract}
Um acordo ou licença entre duas partes, que dá a um grupo de pessoas, os franqueados, o direito de negociar ou utilizar um produto, marca ou negócio. $O$ franqueado tem o direito de utilizar o produto, marca ou negócio do franqueador e em troca o tem o dever de pagar certas taxas e royalties ao franqueador. $O$ franqueador tem ainda o dever de dar suporte, de uma forma geral ao franqueado (IFA 2011, p. 2).
\end{abstract}

Enquanto Cherto (2005) foca a questão mercadológica, a IFA (2011) tem como foco a relação entre franqueado e franqueador, ou seja, um foco mais centrado na questão do relacionamento de rede e replicação do negócio, com direitos e obrigações de ambas as partes. Desta forma, neste trabalho, será utilizada a seguinte terminologia, derivada da definição da IFA (2011):

a) Franqueador (franchisor): entidade detentora de produtos, serviços, marcas ou negócios objetos de replicação com fins de serem explorados comercialmente em outros mercados ou locais;

b) Franqueado (franchisee): entidade que recebe o direito de uso dos produtos, serviços, marcas ou negócios do franqueador;

c) Taxas de franquias e royalties: remuneração a qual o franqueado deve pagar ao franqueador pelo direito de uso cedido na franquia.

No Brasil, o franchising é regulamentado pela Lei 8.955 de 15 de dezembro de 1994. A referida lei define e regulamenta os contratos de franquia empresarial. Em seu artigo $2^{\circ}$ define franquia no Brasil como:

Franquia empresarial é o sistema pelo qual um franqueador cede ao franqueado o direito de uso de marca ou patente, associado ao direito de distribuição, exclusiva ou semi-exclusiva de produtos ou serviços, e eventualmente, também ao direito de uso de tecnologia de implantação e administração de negócio ou sistema operacional desenvolvido ou detido pelo franqueador, mediante remuneração direta ou indireta, sem que no entanto, fique caracterizado vínculo empregatício (Brasil. Lei 8.955, 1994, art. 2).

OLIVO, R. L. F.; MORILHAS, L. J.; NIELSEN, F. A. G.; CARVALHO, D. E. Avaliação de franquias empresariais por meio de múltiplos de receita: um sacrilégio acadêmico desculpável. Revista de Empreendedorismo e Gestão de Pequenas Empresas, v.5, n.2, 2016. 
A lei brasileira, conforme se percebe por seu artigo $2^{\circ}$, define um conceito de franquia empresarial bastante similar à definição da IFA (2011) e do Departamento de Comércio dos Estados Unidos. Observa-se na definição da lei brasileira os mesmos elementos principais presentes na definição da IFA (2011), entre os quais, franqueador, franqueado, remuneração pelo direito de uso da franquia (taxas e royalties), além da questão da exclusividade ou semiexclusividade.

A lei brasileira acrescenta ainda que a franquia não constitui vínculo empregatício, destacando a relativa autonomia, pelo menos jurídica, entre franqueado e franqueador. Essa definição de franquias empresariais, explicitada na lei brasileira, é adotada pelo presente artigo para ser coerente com o universo pesquisado, ou seja, as franquias empresariais no Brasil.

\section{Avaliação por Fluxo de Caixa Descontado (FCD)}

O método de avaliação de empresas pelo Fluxo de Caixa Descontado (FCD) é considerado, em geral, o mais robusto do ponto de vista conceitual e, portanto, aquele que traria os resultados mais acurados para o valor da empresa (DAMODARAN, 2007).

Copeland et al. (2002) defendem o uso do FCD, pois consideram que é o único método que requer informações completas e adota uma visão de longo prazo, a qual se faz necessária para entender a criação de valor. De forma complementar, Damodaran (2007, p. 22) concorda que o método do FCD possui diversas virtudes. Em especial, requer que os analistas entendam o negócio que estão avaliando e seus direcionadores de valor, como a sustentabilidade dos fluxos de caixa em longo prazo e os riscos envolvidos no negócio.

Assim, força os analistas a se deterem nos fundamentos do valor, diminuindo percepções subjetivas e influenciadas por momentos do mercado. $O$ autor evidencia algumas limitações do método, tal como a possibilidade de manipulação por parte de analistas inescrupulosos, mas concorda que o método em si é robusto (DAMODARAN, 2007).

A forma matemática de representar o método do Fluxo de Caixa Descontado

OLIVO, R. L. F.; MORILHAS, L. J.; NIELSEN, F. A. G.; CARVALHO, D. E. Avaliação de franquias empresariais por meio de múltiplos de receita: um sacrilégio acadêmico desculpável. Revista de Empreendedorismo e Gestão de Pequenas Empresas, v.5, n.2, 2016. 
é a seguinte (COPELAND et al., 2002; DAMODARAN, 2007):

$$
\text { Valor }=\sum \frac{F C n}{(1+k)^{n}}
$$

$\mathrm{Na}$ qual,

FC - Fluxos de caixa livres futuros projetados.

$k$ - custo de capital.

Em casos especiais nos quais a empresa em questão é madura, ou seja, os seus fluxos de caixa futuros crescerão a uma taxa média apenas marginal e considerando-se tal taxa constante, pode-se simplificar a representação matemática da Equação 2.1 para uma construção (COPELAND et al., 2002; DAMODARAN, 2007) em que calcula-se o valor da empresa para o proprietário, também chamado de valor do equity:

$$
\text { Valor }=\frac{F C_{0}(1+g)}{(k e-g)}
$$

$\mathrm{Na}$ qual,

$F C_{0}$ - Fluxo de caixa livre atual do proprietário.

ke - custo de capital próprio.

$g$ - taxa de crescimento marginal esperada.

Assim, no caso da empresa madura, os determinantes do seu valor ficam reduzidos basicamente ao seu fluxo de caixa livre atual, ao custo de capital próprio e à taxa de crescimento marginal esperada dos fluxos de caixa, presumida como constante para fins do modelo.

Entende-se por fluxo de caixa livre atual da empresa, o montante financeiro gerado pela operação da empresa disponível para remunerar os seus credores e proprietários. Essa equação 2.2 representa com razoável fidedignidade o valor das unidades franqueadas em sua maturidade, o que acontece em média após 3 ou 4 2016. 
anos de sua constituição. Tal pressuposto será melhor detalhado nesse artigo, na seção Procedimentos Metodológicos.

\section{Estimativa do Custo de Capital Próprio (ke)}

Apesar do fluxo de caixa livre e da taxa de crescimento não serem valores simples de serem estimados, em uma empresa madura pode-se estimá-los com base em seu histórico projetado com razoável grau de confiabilidade, pois justamente a empresa atingiu certa estabilidade nesses valores. O custo do capital próprio, contudo, é mais complexo de ser estimado (ROSS, 2002).

O custo do capital próprio é implícito e costumeiramente não documentado nas demonstrações financeiras das empresas. Na verdade, o que é documentado é a expectativa de retorno desejada pelos proprietários oriundos do capital investido no negócio. Assim, é ela representa o custo de oportunidade do capital investido pelos proprietários na empresa (ROSS, 2002; DAMODARAN, 2007).

O modelo mais empregado de cálculo do custo de capital próprio é o Modelo de Precificação dos Ativos de Capital (CAPM). O modelo proposto originalmente por Sharpe (1963) tem sido adaptado por diversos autores para estimar o custo de oportunidade do capital investido dado o nível de risco da empresa. Tal modelo é baseado na proposição de que a taxa de retorno exigida de qualquer ativo é igual à taxa de retorno livre de risco mais um prêmio de risco proporcional ao risco do negócio em que o ativo será empregado para gerar tal retorno.

Nesse sentido, o custo do capital próprio pode ser expresso pela seguinte proposição (COPELAND et al., 2002; DAMODARAN, 2007):

$$
k e=R f+\beta(R m-R f)
$$

Na qual,

$\mathrm{Rf}=$ taxa livre de risco da economia.

$\beta=$ fator de risco de mercado.

$\mathrm{Rm}=$ retorno esperado do mercado.

OLIVO, R. L. F.; MORILHAS, L. J.; NIELSEN, F. A. G.; CARVALHO, D. E. Avaliação de franquias empresariais por meio de múltiplos de receita: um sacrilégio acadêmico desculpável. Revista de Empreendedorismo e Gestão de Pequenas Empresas, v.5, n.2, 2016. 
Neste trabalho, o CAPM será utilizado como modelo de cálculo para o custo do capital próprio (ke). Contudo, para tal, dois ajustes fazem-se necessários. O primeiro consiste no fato de que as unidades franqueadas são empresas de capital fechado, portanto, não existe um beta explícito para elas. Assim, será utilizado o beta médio dos setores relacionados à atividade da franquia das empresas de capital aberto.

Esse beta calculado refletirá o nível de endividamento das empresas, o que é inadequado para o cálculo do custo do capital próprio. Assim esse beta médio deve ser o beta médio desalavancado, isto para ser adequado ao cálculo do capital próprio.

De acordo com Damodaran (2002, p. 75), pode-se calcular o beta desalavancado da seguinte forma:

$$
\beta u=\beta I /(1+(1-T)(D / E)
$$

Na qual,

$\beta \mathrm{u}=$ beta desalavancado.

$\beta \mathrm{I}=$ beta alavancado.

$T$ - alíquota de imposto de renda.

D - porcentagem de capital de terceiros da empresa.

E - porcentagem de capital próprio da empresa.

O segundo ajuste consiste em considerar o porte das empresas na análise. As empresas de capital aberto que fornecem o beta médio do setor são de porte econômico maior que as unidades franqueadas, as quais são pequenas empresas. Logo, é necessário acrescentar um fator de risco pelo porte ao modelo CAPM a fim de refletir tal diferença. Em pesquisa, Matos e Moura (2003) estimaram quanto deveria ser esse ajuste para as empresas brasileiras, conforme demonstrado na Tabela 1. 2016. 
TABELA 1 - PRÊMIO DE RISCO.

\begin{tabular}{cc} 
Nível de Risco & Prêmio de Risco \\
\hline Muito Baixo & $6 \%$ \\
\hline Baixo & $9 \%$ \\
\hline Médio & $14 \%$ \\
\hline Alto & $21 \%$ \\
\hline Muito alto & $30 \%$
\end{tabular}

FONTE: Matos e Moura (2003).

As unidades franqueadas contam com 0 apoio de redes de franquias, manuais, supervisão e todo tipo de suporte dos franqueadores (ABF, 2016). Matos e Moura (2003) estabeleceram níveis de risco para pequenas empresas brasileiras. Para as franquias, as pesquisas da ABF (2016) indicam que o franqueado, muitas vezes, não possui um perfil ideal de experiência como administrador ou gerente. Por outro lado, o suporte oferecido pelo franqueador contribui para reduzir parcialmente essa inexperiência do franqueado.

Dessa maneira, considerando esses dois efeitos à inexperiência do franqueado, mas parcialmente mitigada pelo apoio do franqueador, o nível de risco correspondente seria a segunda categoria menos arriscada de Matos e Moura (2003), ou seja, o nível de risco "baixo", agregando, portanto, um prêmio de risco de $9 \%$ pelo porte para as unidades franqueadas, conforme demonstrado na Tabela 1.

\section{Avaliação por Múltiplos de Receita}

Um método de avaliação alternativo ao FCD é a chamada avaliação por múltiplos ou avaliação relativa. A lógica dessa forma de avaliação reside em encontrar empresas comparáveis à entidade que se quer avaliar. Por meio de algum

OLIVO, R. L. F.; MORILHAS, L. J.; NIELSEN, F. A. G.; CARVALHO, D. E. Avaliação de franquias empresariais por meio de múltiplos de receita: um sacrilégio acadêmico desculpável. Revista de Empreendedorismo e Gestão de Pequenas Empresas, v.5, n.2, 2016. 
direcionador relevante de valor, em geral lucro ou receita, estima-se o valor da empresa por comparação.

Como exemplo, a fim de ilustrar o método, deseja-se estimar o valor da empresa $A$ e sabe-se que a empresa $B$, que é comparável a empresa $A$, possui um valor de $R \$ 1$ milhão e o seu lucro é de $R \$ 200$ mil. Assim, a empresa $B$ possui um múltiplo de 5, ou seja, o seu valor é cinco vezes o seu lucro anual. Uma vez que a empresa A é comparável a $B$, seria possível tomar por base seu lucro de $R \$ 100$ mil e por comparação com a empresa $\mathrm{B}$, utilizar o múltiplo de 5 . Logo o seu valor seria de $R \$ 500$ mil (lucro de $R \$ 100$ mil vezes o múltiplo 5).

A mesma lógica pode ser aplicada à receita, ao lucro operacional (LAJIR), ou mesmo a múltiplos específicos por setor: preço por metro quadrado na construção civil, preço por litros vendidos na distribuição de combustíveis, preço por número de acessos na internet, entre outros. O maior desafio da avaliação por múltiplos, e talvez a principal fraqueza do método, consiste na dificuldade em encontrar empresas comparáveis, afinal nenhuma empresa é igual à outra (DAMODARAN, 2007).

Ainda segundo Damodaran (2007), geralmente utilizam-se como empresas comparáveis, aquelas que atuam no mesmo setor econômico. Contudo, mesmo essas empresas são, não raramente, muito diferentes entre si em porte, estratégia de negócios, tecnologia, ciclo de vida, entre outros fatores, o que torna difícil a comparação de forma adequada.

Para Damodaran (2007, p. 316) as empresas comparáveis deveriam ser aquelas, não necessariamente do mesmo setor, mas cujos fundamentos - fluxo de caixa, custo de capital (risco) e crescimento esperado - sejam comparáveis. Em outras palavras, o autor propõe uma "ponte" entre os métodos do FCD e dos múltiplos, na medida em que os múltiplos seriam uma simplificação e padronização, sob certas circunstâncias específicas, dos fundamentos do FCD. Assim, Damodaran (2007, p. 389-390) apresenta a "conciliação" entre o múltiplo preço/faturamento (P/F) e os fundamentos de valor (fluxo de caixa, risco e crescimento):

OLIVO, R. L. F.; MORILHAS, L. J.; NIELSEN, F. A. G.; CARVALHO, D. E. Avaliação de franquias empresariais por meio de múltiplos de receita: um sacrilégio acadêmico desculpável. Revista de Empreendedorismo e Gestão de Pequenas Empresas, v.5, n.2, 2016. 
Na qual,

P/F - múltiplo preço dividido por faturamento.

$r$ - taxa de retorno exigida sobre o patrimônio.

$g$ - taxa de crescimento do fluxo de caixa (perpétua).

Devido ao fato de os múltiplos de receita serem os mais utilizados pelo setor de franquias empresariais para avaliar as suas unidades franqueadas, a presente pesquisa analisou esses múltiplos no referido setor a fim de descobrir se a sua utilização é coerente e conduz a resultados razoáveis.

Tendo-se em mente que a principal crítica à avaliação relativa é a questão da comparabilidade e considerando que as franquias são desenhadas justamente para serem réplicas mais perfeitas possíveis entre si, é de se esperar que haja uma convergência entre o FCD e a avaliação por múltiplos nesse setor. Essa é a principal conjectura da presente pesquisa e será mais bem discutida na seção 3 - Método da Pesquisa.

\section{Procedimentos Metodológicos}

Os procedimentos utilizados nesta pesquisa foram escolhidos em conformidade e coerência com o problema de pesquisa. A fim de responder a indagação acerca das vantagens da utilização da avaliação por múltiplos para o setor de franquias empresariais no Brasil, o método mais adequado é o Estudo de Caso. O estudo de caso é definido por Yin (2001) como um método de pesquisa com três características marcantes:

a) Ser uma investigação empírica que estuda um fenômeno contemporâneo dentro de seu contexto de vida real, no qual os limites entre o fenômeno e o contexto não estão claramente definidos;

OLIVO, R. L. F.; MORILHAS, L. J.; NIELSEN, F. A. G.; CARVALHO, D. E. Avaliação de franquias empresariais por meio de múltiplos de receita: um sacrilégio acadêmico desculpável. Revista de Empreendedorismo e Gestão de Pequenas Empresas, v.5, n.2, 2016. 
b) Enfrentar uma situação tecnicamente única em que haverá muito mais pontos de interesse do que fontes de dados, exigindo triangulações de evidências;

c) Beneficiar-se do desenvolvimento prévio de proposições teóricas para conduzir a coleta e análise de dados.

Desse modo, considerando a questão de pesquisa que guia este trabalho, a utilização do método de estudo de caso é bastante adequada à definição de Yin (2001, p. 32), na medida em que a franquia empresarial é um fenômeno contemporâneo, no qual os limites entre o fenômeno e o contexto não estão claramente definidos (item a) e cada rede de franquias é tecnicamente única (item b).

O estudo de caso, de acordo com Yin (2001, p. 61), possibilita basicamente quatro tipos de estudo: (1) projetos de casos únicos holísticos; (2) projetos de casos únicos incorporados; (3) projetos de casos múltiplos holísticos; e (4) projetos de casos múltiplos incorporados. Para o autor, o estudo de caso múltiplo, adotado nesse trabalho, é semelhante a um experimento múltiplo, no qual se busca a replicação teórica do resultado como proposto por Yin (2001).

Os casos escolhidos para a pesquisa foram duas redes de franquias brasileiras: a rede de perfumaria e cosméticos L'acqua di Fiori e a de fast food Lanchão. Tal escolha justifica-se pela relevância dos segmentos a que pertencem cada uma das redes: o segmento de alimentação (ao qual pertence o Lanchão) faturou $\mathrm{R} \$ 27,9$ bilhões em 2015 ou cerca de $20 \%$ do total do setor de franquias no Brasil (ABF, 2016) e o segmento de Esporte, Saúde, Beleza e Lazer (ao qual pertence a L'acqua di Fiori) faturou $R \$ 25,1$ bilhões ou cerca de $18 \%$ do setor de franquias (ABF, 2016).

Assim, esta pesquisa, utilizando-se do método da replicação teórica proposta por Yin (2001) para o Estudo de Caso, comparou, nos dois casos escolhidos, os múltiplos de receita efetivamente praticados nessas redes para a compra e venda de unidades franqueadas com a avaliação pelo FCD das mesmas

OLIVO, R. L. F.; MORILHAS, L. J.; NIELSEN, F. A. G.; CARVALHO, D. E. Avaliação de franquias empresariais por meio de múltiplos de receita: um sacrilégio acadêmico desculpável. Revista de Empreendedorismo e Gestão de Pequenas Empresas, v.5, n.2, 2016. 
unidades franqueadas. Caso os métodos apresentem valores compatíveis entre si, será considerada uma replicação teórica, conforme proposto por Yin (2001).

Para tanto, foram estimados os fundamentos de valor de um negócio, notadamente o seu potencial de crescimento, o seu custo de capital e o seu fluxo de caixa livre, conceitos esses aplicados às franquias selecionadas para os estudos de caso. Levantou-se ainda no mercado, os múltiplos de receita praticados na compra e venda de unidades franqueadas nas redes estudadas a fim de comparar com os resultados obtidos pelo método do FCD.

Dessa maneira, foi criado um intervalo de valor possível para a franquia, considerando-se valores médios da rede como um todo, ou seja, estão computadas lojas de pequeno e grande porte agregadas. Ademais, o franqueador estima um intervalo de margem líquida de lucro e, consequentemente, de fluxo de caixa livre, o qual gera naturalmente um intervalo de valor para as unidades franqueadas, dependendo de sua margem líquida de lucro efetiva da unidade.

O objetivo da comparação foi buscar uma replicação teórica de convergência ou divergência entre as duas formas de avaliação. Nessa linha, se houver convergência, indicará evidências de robustez da avaliação por múltiplos no setor de franquias. Caso haja replicação de divergência, será indicativo da fraqueza da avaliação relativa no setor. Para este estudo, será considerada convergência se o valor estimado da avaliação por múltiplos estiver dentro do intervalo estimado pela avaliação do FCD. Em caso contrário, será considerada uma divergência.

O estudo valeu-se tanto de dados primários obtidos por meio de entrevistas com os franqueadores e alguns franqueados das duas redes, quanto por dados secundários coletados, em especial de publicações da ABF. Os dados foram coletados em 2012, tendo sido escolhidos os setores de alimentação e de higiene e beleza por serem o segundo e terceiro maiores setores no ramo de franquias brasileiras.

As entrevistas coletaram os dados financeiros das franquias. Complementarmente, os dados secundários da ABF permitiram avaliar as margens médias de cada setor de franquia estudado, bem como as expectativas médias de retorno dos franqueados. O cruzamento e análise desses dados, de fontes variadas,

OLIVO, R. L. F.; MORILHAS, L. J.; NIELSEN, F. A. G.; CARVALHO, D. E. Avaliação de franquias empresariais por meio de múltiplos de receita: um sacrilégio acadêmico desculpável. Revista de Empreendedorismo e Gestão de Pequenas Empresas, v.5, n.2, 2016. 
permitiram a triangulação das evidências. Esse procedimento é indispensável para a solidez do método do estudo de caso.

\section{Resultados Obtidos}

Os principais dados obtidos por meio de entrevistas com os franqueadores, triangulação com alguns franqueados e relatórios da $A B F$ foram sumarizados na Tabela 2.

TABELA 2 - FLUXO DE CAIXA ESTIMADO DAS FRANQUIAS.

\begin{tabular}{|c|c|c|c|}
\hline & Lanchão & $\begin{array}{c}\text { L'acqua di } \\
\text { Fiori } \\
\end{array}$ & Fonte \\
\hline $\begin{array}{c}\text { Faturamento médio } \\
\text { mensal de unidade }(\mathrm{R} \$)\end{array}$ & $80.000,00$ & $45.000,00$ & $\begin{array}{c}\text { ABF; entrevista } \\
\text { franqueadores }\end{array}$ \\
\hline $\begin{array}{l}\text { (a) Faturamento médio } \\
\text { anual de unidade }(\mathrm{R} \$)\end{array}$ & $960.000,00$ & $540.000,00$ & $\begin{array}{c}\text { ABF; entrevista } \\
\text { franqueadores }\end{array}$ \\
\hline $\begin{array}{l}\text { (b) Margem líquida } \\
\text { inferior de lucro (\%) }\end{array}$ & $10 \%$ & $8 \%$ & $\begin{array}{r}\text { ABF; entrevista } \\
\text { franqueadores }\end{array}$ \\
\hline $\begin{array}{l}\text { (c) Margem líquida } \\
\text { superior de lucro }(\%)\end{array}$ & $15 \%$ & $15 \%$ & $\begin{array}{r}\text { ABF; entrevista } \\
\text { franqueadores }\end{array}$ \\
\hline $\begin{array}{l}\text { Reinvestimento } \\
\text { do lucro }(\%) \\
\end{array}$ & $20 \%$ & $10 \%$ & $\begin{array}{c}\text { Entrevista } \\
\text { franqueadores }\end{array}$ \\
\hline $\begin{array}{l}\text { Fluxo de caixa livre - faixa } \\
\text { inferior ( } \mathrm{R} \$ \text { ao ano) }\end{array}$ & $76.800,00$ & $38.880,00$ & (a) $\mathrm{x}(\mathrm{b}) \mathrm{x}(1-\mathrm{d})$ \\
\hline $\begin{array}{c}\text { Fluxo de caixa livre - faixa } \\
\text { superior }(\mathrm{R} \$ \text { ao ano })\end{array}$ & $11520000 \%$ & $7290000 \%$ & (a) $\times($ c) $x(1-d)$ \\
\hline $\begin{array}{l}\text { Crescimento estimado para } \\
\text { a perpetuidade }(\mathrm{g})\end{array}$ & 0,01 & 0,02 & $\begin{array}{c}\text { Entrevista } \\
\text { franqueadores }\end{array}$ \\
\hline
\end{tabular}

FONTE: ABF (2016) e entrevistas com franqueadores.

\section{Resultados da Avaliação por FCD}

A fim de aplicar o método do FCD ao estudo de caso, foi necessário inicialmente estimar o custo de capital próprio (ke). Assim, foram estimados os betas desalavancados das unidades franqueadas, utilizando-se a Equação 2.4, com alíquota marginal de imposto de $34 \%$ (imposto de renda de $25 \%$ e contribuição

OLIVO, R. L. F.; MORILHAS, L. J.; NIELSEN, F. A. G.; CARVALHO, D. E. Avaliação de franquias empresariais por meio de múltiplos de receita: um sacrilégio acadêmico desculpável. Revista de Empreendedorismo e Gestão de Pequenas Empresas, v.5, n.2, 2016. 
social sobre o lucro de $9 \%$, somados). Os resultados estão demonstrados nas Tabelas 3 e 4.

TABELA 3 - ESTIMATIVA DO BETA DO LANCHÃO.

\begin{tabular}{lccccc} 
Estimativa de beta para & $\begin{array}{c}\text { Beta } \\
\text { Lanchão }\end{array}$ & $\begin{array}{c}\text { Código } \\
\text { Alavancado }\end{array}$ & $\begin{array}{c}\text { Capital de } \\
\text { Bovespa }\end{array}$ & $\begin{array}{c}\text { Capital } \\
\text { Terceiros (\%) }\end{array}$ & $\begin{array}{c}\text { Próprio (\%) } \\
\text { Desalavancado }\end{array}$ \\
\hline Ambev & 0,40 & AMBV4 & $40,20 \%$ & $59,80 \%$ & 0,28 \\
Aliansce Shopping Centers & 0,45 & ALSC3 & $41,87 \%$ & $58,13 \%$ & 0,31 \\
BR Malls Part & 0,70 & BRML3 & $46,69 \%$ & $53,31 \%$ & 0,44 \\
BRF - Brasil Foods & 0,71 & BRFS3 & $51,92 \%$ & $48,08 \%$ & 0,41 \\
Excelsior Alimentos & 0,96 & BAUH3 & $79,84 \%$ & $20,16 \%$ & 0,27 \\
General Shopping Brasil & 0,45 & GSPH3 & $66,55 \%$ & $33,45 \%$ & 0,19 \\
Iguatemi Shopping Centers & 0,61 & IGTA3 & $45,32 \%$ & $54,68 \%$ & 0,39 \\
M Dias Alimentos & 0,67 & MDIA3 & $26,51 \%$ & $73,49 \%$ & 0,54 \\
Média & $\mathbf{0 , 6 2}$ & & & & $\mathbf{0 , 3 5}$ \\
\hline FONTE: BMFBovespa
\end{tabular}

FONTE: BMFBovespa e website comdinheiro.com.br

TABELA 4 - ESTIMATIVA DO BETA DA LACQUA DI FIORI.

\begin{tabular}{lccccc} 
Estimativa de beta para & $\begin{array}{c}\text { Beta } \\
\text { L'acqua di Fiori }\end{array}$ & $\begin{array}{c}\text { Código } \\
\text { Alavancado }\end{array}$ & $\begin{array}{c}\text { Capital de } \\
\text { Bovespa }\end{array}$ & $\begin{array}{c}\text { Capital } \\
\text { Terceiros (\%) }\end{array}$ & $\begin{array}{c}\text { Betáprio (\%) } \\
\text { Pesalavancado }\end{array}$ \\
\hline Aliansce Shopping Centers & 0,45 & ALSC3 & $41,87 \%$ & $58,13 \%$ & 0,31 \\
BR Malls Part & 0,70 & BRML3 & $46,69 \%$ & $53,31 \%$ & 0,44 \\
BR Pharma & 0,65 & BPHA3 & $34,18 \%$ & $65,82 \%$ & 0,48 \\
DIMED - Distrib. Medicamentos & 0,48 & PNVL3 & $50,24 \%$ & $49,76 \%$ & 0,29 \\
Drogasil & 0,59 & DROG3 & $36,45 \%$ & $63,55 \%$ & 0,43 \\
General Shopping Brasil & 0,45 & GSPH3 & $66,55 \%$ & $33,45 \%$ & 0,19 \\
Iguatemi Shopping Centers & 0,61 & IGTA3 & $45,32 \%$ & $54,68 \%$ & 0,39 \\
Natura Cosméticos & 0,51 & NATU3 & $72,76 \%$ & $27,24 \%$ & 0,18 \\
Profarma & 0,46 & PFRM3 & $45,30 \%$ & $54,70 \%$ & 0,30 \\
Raia & 0,61 & RAIA3 & $40,93 \%$ & $59,07 \%$ & 0,42 \\
Média & $\mathbf{0 , 5 5}$ & & & & $\mathbf{0 , 3 4}$ \\
\hline
\end{tabular}

FONTE: BMFBovespa e website comdinheiro.com.br

As outras premissas adotadas para estimar-se o custo de capital próprio, tomando-se como modelo o CAPM, foram:

OLIVO, R. L. F.; MORILHAS, L. J.; NIELSEN, F. A. G.; CARVALHO, D. E. Avaliação de franquias empresariais por meio de múltiplos de receita: um sacrilégio acadêmico desculpável. Revista de Empreendedorismo e Gestão de Pequenas Empresas, v.5, n.2, 2016. 
a) Taxa livre de risco (Rf): adotada a taxa de $9 \%$ ao ano, como expectativa da taxa selic futura a ser praticada no Brasil nos próximos anos;

b) Retorno esperado do mercado $(\mathrm{Rm})$ : adotada a taxa de 13,7\% ao ano como expectativa para os próximos anos, fruto da extrapolação da média geométrica dos retornos do lbovespa de junho de 2001 a junho de 2011;

c) Prêmio de risco pelo porte: adotado 9\%, conforme estudo de Matos e Moura (2003).

\section{Resultados da Avaliação por FCD do Lanchão}

Aplicando-se os modelos de estimativa de custo de capital próprio e estimativa do valor da empresa para o proprietário do Lanchão, tem-se:

$$
\begin{aligned}
& \mathrm{Ke}=\mathrm{Rf}+\beta(\mathrm{Rm}-\mathrm{Rf})+\text { risco pelo porte } \\
& \mathrm{Ke}=9 \%+0,35(13,7 \%-9 \%)+9 \% \\
& \mathrm{Ke}=19,65 \% \\
& \text { Valor }=\frac{F C(1+g)}{(k e-g)}
\end{aligned}
$$

Valor limite inferior $=R \$ 76.800 \times(1,01) /(0,1965-0,01)$

Valor limite inferior $=R \$ 415.914,21$

Valor limite superior $=R \$ 115.200 \times(1,01) /(0,1965-0,01)$

Valor limite superior $=\mathrm{R} \$ 623.871,31$

Por meio do método do fluxo de caixa descontado, o valor de uma unidade franqueada média do Lanchão foi estimado no intervalo de $R \$ 416$ mil a $R \$ 624$ mil. 


\section{Resultados da Avaliação por FCD da L’acqua Di Fiori}

Aplicando-se os modelos de estimativa de custo de capital próprio e estimativa do valor da empresa para o proprietário da L'acqua di Fiori, tem-se:

$$
\begin{gathered}
\mathrm{Ke}=\mathrm{Rf}+\quad \begin{array}{c}
\beta(\mathrm{Rm}-\mathrm{Rf})+\text { risco pelo porte } \\
\mathrm{Ke}=9 \%+0,34(13,7 \%-9 \%)+9 \% \\
\mathrm{Ke}=19,60 \%
\end{array} \\
\text { Valor }=\frac{F C(1+g)}{(k e-g)}
\end{gathered}
$$

Equação 2.2

Valor limite inferior $=R \$ 38.800 \times(1,015) /(0,1960-0,015)$

Valor limite inferior $=\mathrm{R} \$ 217.580,11$

Valor limite superior $=R \$ 72.900 \times(1,015) /(0,1960-0,015)$

Valor limite superior $=R \$ 408.803,87$

Pelo método do fluxo de caixa descontado, o valor de uma unidade franqueada média da L'acqua di Fiori foi estimado no intervalo de $R \$ 218$ mil a $R \$$ 409 mil.

\section{Resultados da Avaliação por Múltiplos}

Os resultados obtidos aplicando-se a avaliação por múltiplos aos casos estudados foram resumidos na Tabela 5 .

OLIVO, R. L. F.; MORILHAS, L. J.; NIELSEN, F. A. G.; CARVALHO, D. E. Avaliação de franquias empresariais por meio de múltiplos de receita: um sacrilégio acadêmico desculpável. Revista de Empreendedorismo e Gestão de Pequenas Empresas, v.5, n.2, 2016. 
TABELA 5 - VALOR DAS FRANQUIAS PELO MÉTODO DOS MÚLTIPLOS

\begin{tabular}{cccc}
$\begin{array}{c}\text { Avaliação por } \\
\text { múltiplos de receita }\end{array}$ & Lanchão & $\begin{array}{c}\text { L'acqua di } \\
\text { Fiori }\end{array}$ & Fonte \\
\hline $\begin{array}{c}\text { (a) Múltiplo de receita } \\
\text { mensal }\end{array}$ & 6,0 & 5,0 & $\begin{array}{c}\text { Entrevista } \\
\text { franqueadores } \\
\text { (b) receita mensal }\end{array}$ \\
$\begin{array}{c}\text { Entrevista } \\
\text { média - unidade (R } \$)\end{array}$ & $8000000 \%$ & 45000 & franqueadores \\
\hline & & & \\
Valor da franquia & $480.000,00$ & $225.000,00$ & (a) $x$ (b)
\end{tabular}

FONTE: entrevistas com franqueadores.

Tomando-se por base os múltiplos praticados na compra e venda de unidades franqueadas das duas redes estudadas, o valor estimado de uma franquia da L'acqua di Fiori foi de $R \$ 225$ mil e do Lanchão de $R \$ 480$ mil.

\section{Considerações Finais}

Os resultados obtidos pelos dois métodos de avaliação, ou seja, pelo método do fluxo de caixa descontado e pelo método dos múltiplos de receita, apresentaram convergência de resultados, como ilustrado na Figura 1. 
FIGURA 1 - RESUMO DOS RESULTADOS OBTIDOS.

\section{Lanchão}

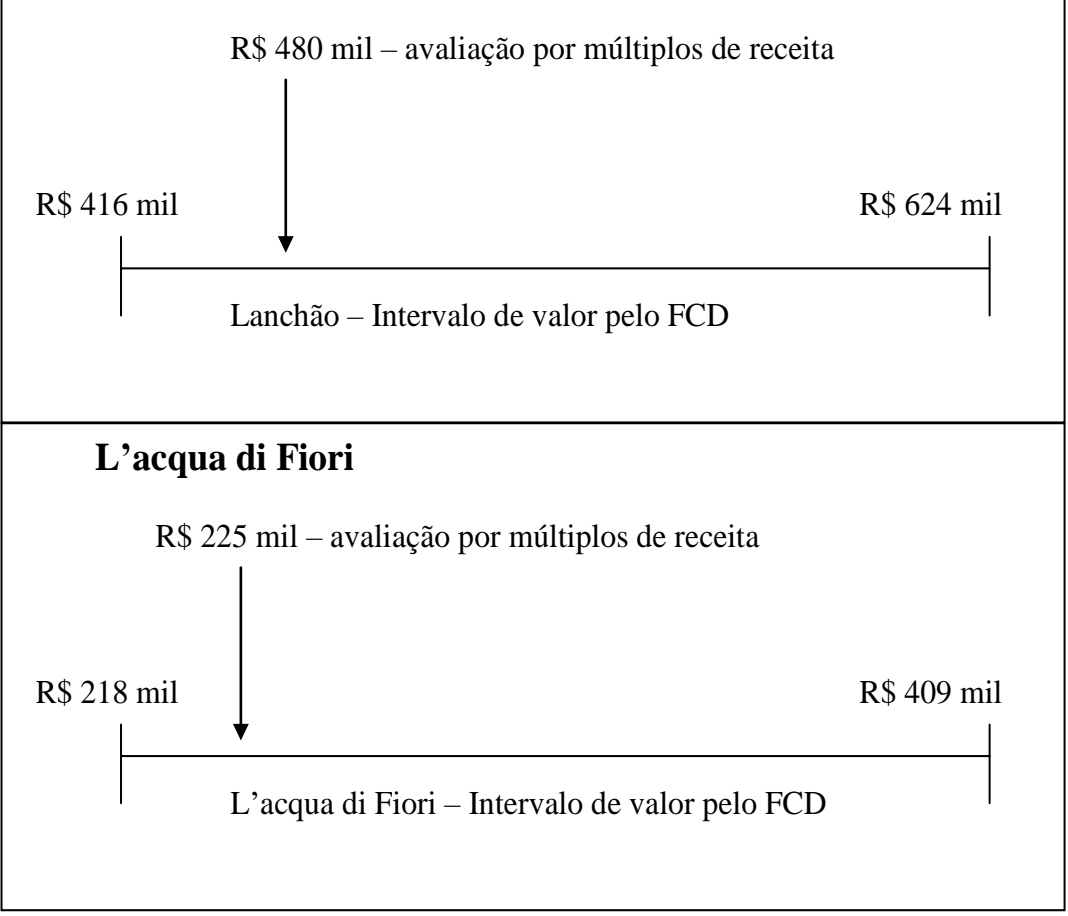

FONTE: Dados da pesquisa.

Observa-se, em relação ao Lanchão, que o valor obtido por meio dos múltiplos ( $\mathrm{R} \$ 480$ mil) está dentro do intervalo de valor estabelecido pelo método do Fluxo de Caixa Descontado, ou seja, os métodos convergiram para valores similares. O mesmo ocorreu em relação a L'acqua di Fiori, cujo valor estimado por meio dos múltiplos de receita ( $R \$ 225$ mil) também se encontra dentro da faixa de valores estimada pelo método do FCD.

Uma vez que ambos os casos apresentaram essa convergência de valores, houve uma replicação teórica dos resultados dos estudos de caso, indicando evidências de que os múltiplos de receita podem sim possibilitar uma mensuração razoavelmente acurada para as franquias no Brasil, visto que suas estimativas são coerentes com as do FCD. Tal evidência é coerente com a teoria, a qual ressalta que os múltiplos são aplicáveis a empresas ou negócios com fundamentos de valor semelhantes, ou seja, empresas com potencial de crescimento, custo de capital e fluxo de caixa livre similares.

OLIVO, R. L. F.; MORILHAS, L. J.; NIELSEN, F. A. G.; CARVALHO, D. E. Avaliação de franquias empresariais por meio de múltiplos de receita: um sacrilégio acadêmico desculpável. Revista de Empreendedorismo e Gestão de Pequenas Empresas, v.5, n.2, 2016. 
As franquias são justamente um exemplo de empresas criadas para serem as mais semelhantes possíveis umas das outras, sendo inclusive essa a proposta básica do modelo de negócios: replicar o sucesso de unidades instaladas em outras localidades. Logo, também é razoável supor que por conta dessa replicação de unidades exista uma convergência nos fundamentos de valor devido ao potencial de crescimento, custo de capital e fluxo de caixa, o que torna o método dos múltiplos de receita apropriado para a análise como demonstraram os casos estudados.

Os resultados obtidos também sugerem que o método dos múltiplos de receita tende a ser mais conservador do que o FCD, uma vez que suas estimativas estão bem próximas do limite inferior do intervalo de valor do que do limite superior. No caso do Lanchão, a avaliação por múltiplos estimou seu valor em $R \$ 480$ mil, valor mais próximo do limite inferior de $R \$ 416$ mil do que do limite superior de $R \$$ 624 mil. O mesmo ocorreu no caso da L'acqua di Fiori, cujo valor estimado pelo múltiplo, de $R \$ 225$ mil, está mais próximo do limite inferior de $R \$ 218$ mil do que do limite superior de $\mathrm{R} \$ 409$ mil.

Uma explicação possível para isso seria que o método dos múltiplos de receita, justamente por trabalhar com menos informações que o FCD, tende a superestimar o custo de capital da franquia em função da sua menor capacidade de estimar o risco implícito na avaliação, gerando assim valores inferiores a média dos valores estimados pelo FCD. Contudo, devido ao próprio método de pesquisa adotado por esse trabalho, bem como pelo seu escopo, tal explicação é uma possibilidade que não foi explorada, apenas sugerida pelos resultados obtidos. Essa pode ser considerada como uma primeira limitação da pesquisa realizada.

Uma segunda limitação seria o próprio método do estudo de caso que, apesar de permitir uma análise interessante das franquias, não permite uma generalização estatística dos resultados obtidos. Desse modo, sugere-se como continuidade desse trabalho, uma nova pesquisa com base de dados ampla de franquias a fim de comprovar estatisticamente a convergência dos métodos dos múltiplos de receita e do FCD, bem como de explorar a sugestão de que a avaliação por meio de múltiplos tende a superestimar o custo de capital em comparação com o FCD.

OLIVO, R. L. F.; MORILHAS, L. J.; NIELSEN, F. A. G.; CARVALHO, D. E. Avaliação de franquias empresariais por meio de múltiplos de receita: um sacrilégio acadêmico desculpável. Revista de Empreendedorismo e Gestão de Pequenas Empresas, v.5, n.2, 2016. 
Finalmente, os resultados obtidos por meio de uma replicação teórica de estudos de caso poderiam ser confirmados ou não com uma pesquisa que utilizasse amostragem probabilística sobre a base de dados da Associação Brasileira de Franchising (ABF), utilizando-se para tal as ferramentas estatísticas adequadas e assim contribuindo para um conhecimento mais profundo nas avaliações de franquias empresariais no Brasil.

\section{Referências:}

ABF, Associação Brasileira de Franchising. Informações e análises do setor. 2016 Disponível em <http://www.abf.com.br>. Acesso em: 20 abr. 2016.

BMFBOVESPA. Bolsa brasileira de valores e mercadorias. Disponível em < http://www.bmfbovespa.com.br/pt_br/produtos/listados-a-vista-e-derivativos/rendavariavel/empresas-listadas.htm>. Acesso em: 17 nov. de 2011.

Brasil. Lei 8.955, de 15 de dezembro de 1994. Dispõe sobre o contrato de franquia empresarial (franchising) e dá outras providências. Disponível em: < http://www.planalto.gov.br/ccivil_03/leis//8955.htm>. Acesso em: 20 abr. 2016.

CHERTO, M. et al. Guia Oficial do Instituto Franchising 2005. São Paulo: ADC Editora, 2005.

COMDINHEIRO. Site de informações e análises do mercado financeiro brasileiro, supervisionado por professores da FEA/USP. Disponível em: < https://www.comdinheiro.com.br/Fundamentalista1-0-0-0-PETR4-0-0-comdinheiro1>. Acesso em: 18 nov. de 2011.

COPELAND, T. et al. Avaliação de Empresas "Valuation" - Calculando e gerenciando o valor das empresas. 3. ed. São Paulo: Pearson, 2002.

DAMODARAN, A. Avaliação de Empresas. 2. ed. São Paulo: Pearson, 2007.

A Face Oculta da Avaliação. São Paulo: Makron Books, 2002.

FEYERABEND, P. Contra o método. São Paulo: editora Unesp, 2007.

IFA, International Franchise Association. Apresenta Informações sobre franchising no mundo. 2011. Disponível em: <http://www.franchise.org.>. Acesso em: 18 nov. 2011.

LAKATOS, E. M.; MARCONI, M. A. Metodologia científica. São Paulo: Atlas, 2001.

OLIVO, R. L. F.; MORILHAS, L. J.; NIELSEN, F. A. G.; CARVALHO, D. E. Avaliação de franquias empresariais por meio de múltiplos de receita: um sacrilégio acadêmico desculpável. Revista de Empreendedorismo e Gestão de Pequenas Empresas, v.5, n.2, 2016. 
MATOS, D. M.; MOURA, H. J. Proposta de um Modelo para Determinação do Custo de Capital Baseado em Análise Hierárquica. RAC, v. 7, n. 4, p. 119-139, 2003.

ROSS, S. A.; WESTERFIELD, R. W.; JAFFE, J. F. Administração Financeira: Corporate Finance. São Paulo: Atlas, 2002.

SELLTIZ, C. et al. Método de pesquisa nas relações sociais. São Paulo: Pedagógica Universitária, 1974.

YIN, R. K. Estudo de Caso: Planejamento e Métodos. Porto Alegre: Bookman, 2001. 